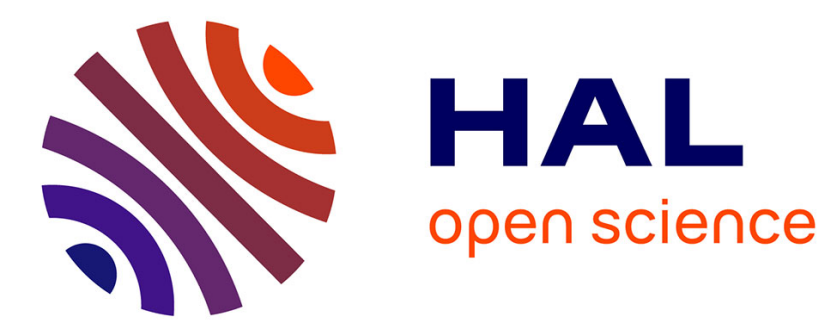

\title{
Electrical design and simulation of kinetic piezoelectric harvester for distributed control cells.
}

Barcola Essodong, Micky Rakotondrabe, Morvan Ouisse, Ausrine Bartasyte

\section{To cite this version:}

Barcola Essodong, Micky Rakotondrabe, Morvan Ouisse, Ausrine Bartasyte. Electrical design and simulation of kinetic piezoelectric harvester for distributed control cells.. Sensors for Next-Generation Robotics, Apr 2016, Baltimore, United States. hal-02393284

\section{HAL Id: hal-02393284 \\ https://hal.science/hal-02393284}

Submitted on 4 Dec 2019

HAL is a multi-disciplinary open access archive for the deposit and dissemination of scientific research documents, whether they are published or not. The documents may come from teaching and research institutions in France or abroad, or from public or private research centers.
L'archive ouverte pluridisciplinaire HAL, est destinée au dépôt et à la diffusion de documents scientifiques de niveau recherche, publiés ou non, émanant des établissements d'enseignement et de recherche français ou étrangers, des laboratoires publics ou privés. 


\title{
Electrical design and simulation of kinetic piezoelectric harvester for distributed control cells
}

\author{
Essodong Barcola ${ }^{1}$, Micky Rakotondrabe ${ }^{1} *$, Morvan Ouisse $^{2}$ and Ausrine Bartasyte ${ }^{3}$ \\ ${ }^{1}$ dept of Automatic Control and MicroMechatronic Systems (AS2M) \\ 2 dept of Applied Mechanics (DMA) \\ 3 dept of MicroNano Sciences and Systems (MN2S) \\ all from the FEMTO-ST Institute \\ UBFC, Université de Franche-Comté, ENSMM, CNRS, UTBM, \\ 24, rue Alain Savary Besançon, France; \\ *: corresponding author: mrakoton@femto-st.fr
}

\begin{abstract}
This paper deals with the design, the modeling and the simulation of two electrical circuits devoted to kinetic piezoelectric energy harvesters for powering distributed control cells. Two schemes are proposed, analyzed and discussed: the first is a based on classical electrical stages, and the second integrates a novel multiplier/rectifier stage which permits to reduce the voltage loss. Simulation and experimental tests are carried out and demonstrate the advantage of the second scheme relative to the first one.
\end{abstract}

Keywords: Piezoelectric energy harvesting, electrical circuit, booster, rectifier, voltage multiplier, oscillator, adaptator.

\section{INTRODUCTION}

This paper is within the context of distributed control cells in ${ }^{1}$ where one cell is considered as an independant mechatronic module with embedded sensing, actuation, control and power source. One of the application of the distributed control cells is the distributed damping of vibrations in a vibrating environment such as in cars chassis. Several projects in link with the above context deal with the sensing, the actuation and the control, for example the C-MUMS project ${ }^{2}$. However this paper is within the project that studies the power source of each cell and in which alternative ways than batteries are studied.

In an environment with ambiant vibrations, it is possible to extract the vibrational energy and transform it into electrical energy. Vibrational piezoelectric energy harvesting (VPEH) is an approach known for that. In fact VPEH has been given increasing attention these last twenty years. This is thanks to the increasing trend towards autonomous miniaturized apparatuses with low energy consumption ${ }^{3-5}$. In a VPEH, the principle consists in scavenging the vibrational energy with a piezoelectric structure and an electrical circuit. The piezoelectric structure transforms the piezoelectric material deformation due to the external vibrational movement into varying electrical voltage, and the circuit conditions this latter into a more exploitable source (regulated and eventually amplified voltage, regulated power).

In order to be able to extract more and more energy from smaller and smaller piezoelectric structures, the research in VPEH can be classified into five categories. The first category studies the possibility to increase the piezoelectric layers within the transducer structure ${ }^{6-10}$. If the layers number is increased, the recuperated voltage is increased. A challenge in this category is the difficulty to realize the multilayered structure when the expected total thickness is less than the millimeter. Recent research shows that such realization could be possible if performed with clean-room processes ${ }^{11}$. The second category of research in VPEH deals with combining piezoelectric transduction with another type of transduction ${ }^{12-15}$. Called hybrid PEH, the approach permits to obtain larger power since the total output power is a combination of that from the PEH with that of the second transducer which can be thermal, magnetic, solar. Nowadays, a limitation of hybrid PEH is the size: the total dimensions of the harvester increase with the number of transducers. Another category of VPEH research is focused on how to make the harvester sensitive to different vibrations frequency (broadband harvesters) ${ }^{16-19}$. 
Because the output power is directly related to the frequency of the vibrations, classical VPEH are only efficient for a given frequency. In this category therefore, the objective is to develop harvesters utilizable at various excitation frequency. The fourth category in VPEH research focuses on the improvement of the piezoelectric material itself ${ }^{20-22}$. In particular, Lithium Niobate materials are shown to be a good alternative material face to lead-zirconate-titanate (PZT) ${ }^{23,24}$. They are lead-free materials and could provide performances that concurrent those of PZT. Finally, the last but not the least, the research on the electrical circuit itself constitutes a category in VPEH research. The endeavor is to develop circuits with less consumption, more efficient energy transfer and conversion as well as more efficient voltage adaptation and regulation ${ }^{25-28}$.

This paper lies in the last category. It presents our first studies on electrical circuit for VPEH devoted to one control cell. The first contribution of the paper is the suggestion of an electrical scheme on the basis of combination of classical electrical stages. In the second contribution, we introduce a new stage that serves as voltage multiplier and rectifier simultaneously. The two electrical schemes are discussed, simulated and tested. For that, the paper is organized as follows. Section-2 presents the first electrical circuit. Both simulation and experimental results are presented in the same section. In section-3, the suggested second circuit is detailed. Again, both simulation and experimental results are presented. The last section deals with discussions, concluding remarks and future works.

\section{AN ELECTRICAL CIRCUIT BASED ON STANDARD STAGES}

Generally, the output signals of a piezoelectric structure in a VPEH are not favourable. The output voltage is alternating and could be of high amplitude, the output current is low (and so is the power), and the output impedence is capacitive ${ }^{29}$. It is therefore important to adapt the output signals with respect to the requirements and with respect to the load, where constant and regulated voltages are often required. The basic and classical electrical circuit for a PVEH is a four diodes based rectifier with a smoothing and filtering capacitor ${ }^{30}$. This simple technique has several limitations. First when the piezoelectric transducer furnishes low amplitude alternating votage, the diodes absorb it and there is not anymore exploitable voltage at the output of the circuit. If the voltage amplitude is too low, the diodes may not even work. Additionally to that, if there is a variation of the vibrations amplitude which directly affects the alternating voltage of the piezoelectric transducer, the output DC voltage also varies and is not regulated. Finally, with this simple circuit, the output DC voltage itself and the output power depend on the load. In this section, we suggest an electrical scheme based on existing stages in the literature in order to bypass some of these limitations.

\subsection{The electrical scheme}

Let Fig. 1 depicts the whole block-diagram of the proposed electrical circuit and the piezoelectric transducer. The piezoelectric structure transducer is excited by external vibrations at a frequency $f_{o}$ and oscillates with an amplitude $\delta$. Thanks to the direct piezoelectric effect, charge $Q$ appears at its electrodes. Therefore, due to the internal capacitor of the piezoelectric element, an alternating voltage $u_{p}$ also appears accross it. Following the technique suggested in ${ }^{29}$ and references herein, we suggest to add a booster in order to amplify the amplitude of $u_{p}$ such that there is s sufficient voltage to run the rectifier. Then the alternating output $u_{b}$ is transformed into DC voltage $u_{\text {rect }}$ with a rectifier and a smoothing capacitor stage. Finally, the last stage deals with transforming the DC voltage $u_{\text {rect }}$ into the required votage $u$, either by multiplying or dividing it, by regulating this latter, and eventually by adapting the output impedence. Specifically the impedence adaptor can be designed to disconnect the load from the upstream stages, so that the output power and output voltage become independent from the vibrations frequency $f_{o}$.

Fig. 2 depicts the booster, the rectifier and the smoothing capacitor stages. The booster is a nonlinear circuit composed of an inductance and two switches. Called SSHI (synchronized switch harvesting in inductor) ${ }^{29}$, its principle consists in detecting the extremum (resp. positive or negative) and, when the extremum is detected, closing the switch thanks to the nonlinear circuit (resp. positive alternance switch or negative alternance switch) during a very few delay relative to the period $\frac{1}{f_{o}}$. By doing so, the output voltage $u_{b}$ is a combination of the voltage from the inductor and that from the piezoelectric transducer. Other schemes of booster can be found in the literature, for instance in ${ }^{29}$ and references herein. They are principally nonlinear circuits. Finally, as depicted in Fig. 2, the suggested rectifier is based on a four diodes bridge. 


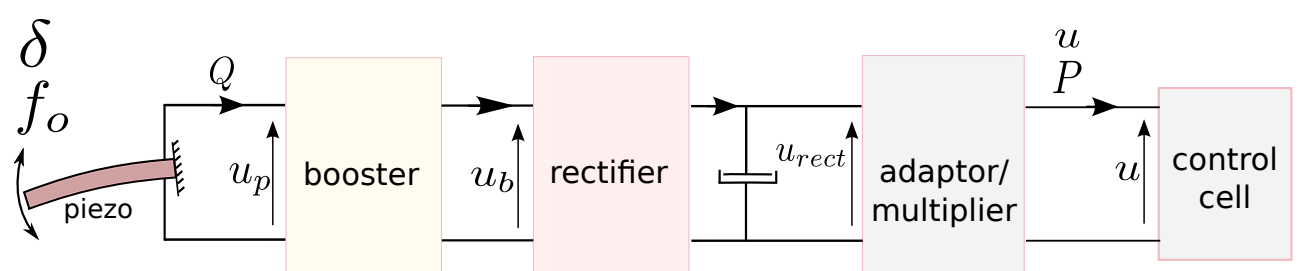

Figure 1: Block diagram of the electrical circuit.

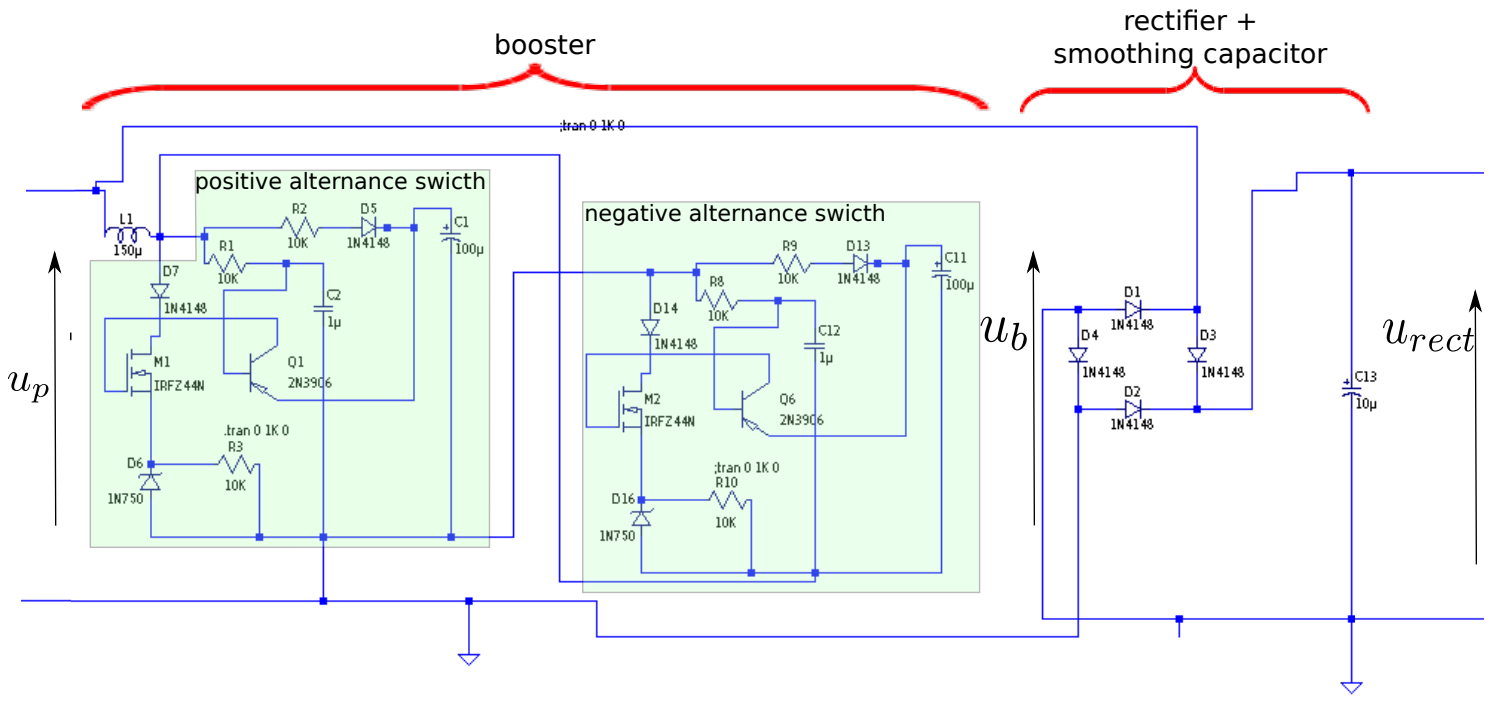

Figure 2: The booster and the rectifier.

Without considering the impedence adaptor, let Fig. 3 depicts the suggested voltage multiplier. In order to multiply the DC voltage $u_{\text {rect }}$ however, a rectangular (or square) signal is first required. We therefore add an oscillator as shown in the figure. Since the input of the oscillator is a DC voltage, it has the same objective than an electronic chopper. Then according to the wanted multiplication factor, a series of diode and capacitor systems is proposed for the multiplier itself. Finally, if an impedence adaptor is required, it can be placed before the oscillator or after the multiplier. It worthy that the output power and output voltage depend on the frequency $f_{o}$ of the oscillating piezoelectric element, and consequently on the frequency of the alternating voltage $u_{p}$. However, in our case, the adaptor can be designed so that the load to which is applied $u$ is virtually disconnected from these upstream stages, and consequently $u$ is independant from the frequency $f_{o}$. It is one of the significances of the proposed scheme in Fig. 1.

\subsection{Simulation}

The electrical circuit suggested in Fig. 1 and detailed in Fig. 2 and Fig. 3 has been simulated using LTSPICE software. During the simulation, a low frequency voltage generator is used rather than a piezoelectric circuit, this latter being non-implementable in the software. All the diodes used are based on the 1N4148 type, the NPN transistors on the 2N2222, the PNP transistors on the 2N3906 and the MOSFET transistors on the IRFZ44N. All the simulation and experimental tests were carried out with low frequency $f_{o}$ because the application context is expected to work at low frequency vibrational environments.

First, a sine input voltage $u_{p}$ with amplitude of $1 \mathrm{~V}$ and a frequency of $1 \mathrm{~Hz}$ has been applied. Fig. 4-a shows the evolution of the output voltage $u$ over the time. The figure shows that the voltage transient part takes several tens of seconds before reaching the nominal voltage. Furthermore, the output nominal voltage is less than the input applied voltage, i.e. less than $1 V$, and the total gain between the amplitude of $u_{p}$ and the output voltage $u$ is less than 1 . This is due to voltage loss absorbed by the components used in the electrical circuit. In particular, each diode requires an amount of voltage when conducting. Now, we simulate the circuit with an input voltage 
$u_{p}$ having an amplitude of $2 \mathrm{~V}$. Fig. 4 -b shows the results. It shows that the output voltage largely exceeds $3 \mathrm{~V}$ when observed for several hundreds of seconds. Consequently the voltage gain is almost six times higher than the previous test. In fact, the voltage loss in the different components has been covered and thus the circuit starts to work correctly and to amplify the voltage. The circuit has also been simulated at higher frequencies but similar results and remarks are obtained.

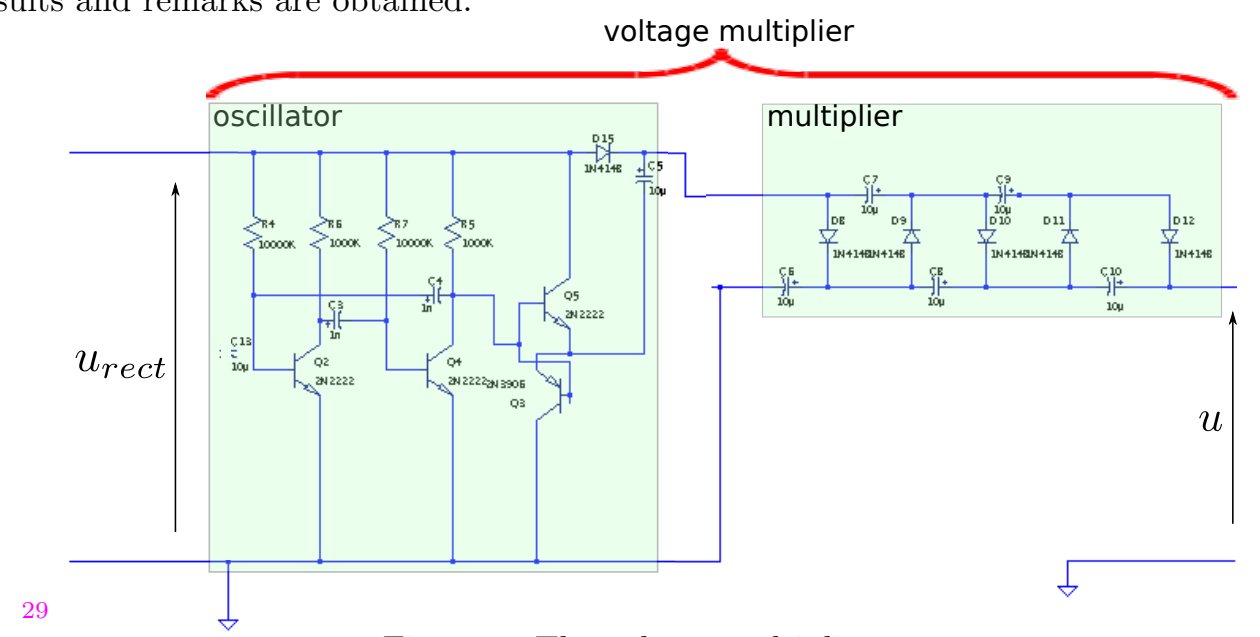

Figure 3: The voltage multiplier.
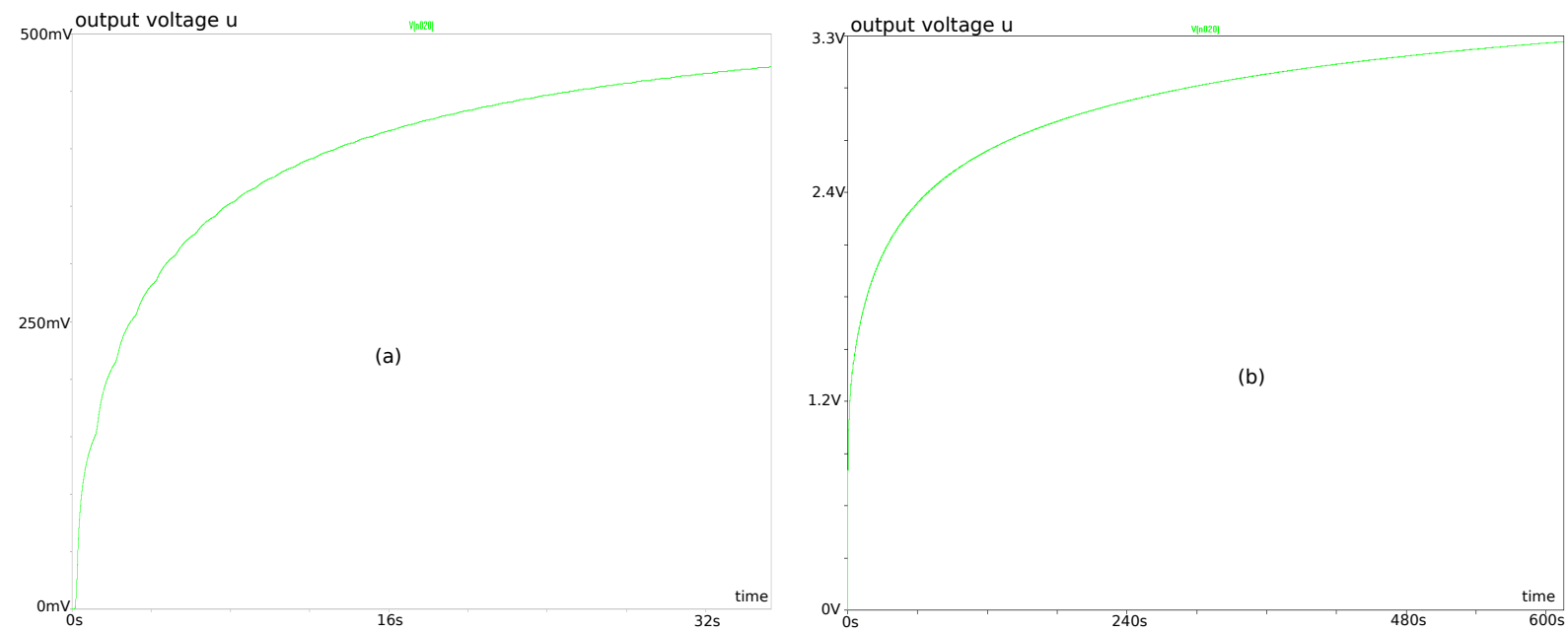

Figure 4: Simulation results: output voltage $u$. (a): with an input voltage $u_{p}=1 V \times \sin (2 \times \pi \times 1 H z \times t)$. (b): with an input voltage $u_{p}=2 \mathrm{~V} \times \sin (2 \times \pi \times 1 H z \times t)$.

\subsection{Experimental results}

The circuit in Fig. 1 has been realized with the same components used for the simulation. A piezoelectric cantilever structure commercially available was first tested as transducer to supply $u_{p}$. Due to the very low voltage of the piezoelectric transducer (tens of milliVolts) which is insufficient to make the components start working, we finally used a voltage generator to supply $u_{p}$. First, a sine voltage $u_{p}$ with an amplitude of $1 V$ and frequency of $1 \mathrm{~Hz}$ is tested. Contrary to the simulation results which showed a reduced output voltage $(u \approx 500 \mathrm{mV})$, the experiments provide an output $u$ of about $2.5 \mathrm{~V}$. The reason of this difference between the simulation and the experimental results might be the voltage consumption in the simulated circuit which could differ from that of the realized circuit. Then, the same amplitude $(1 V)$ of input but with higher frequency $(10 \mathrm{~Hz})$ has been tested. We obtain an output $u$ of about $3 \mathrm{~V}$ as depicted in Fig. 5 in which the output voltage $u$. 


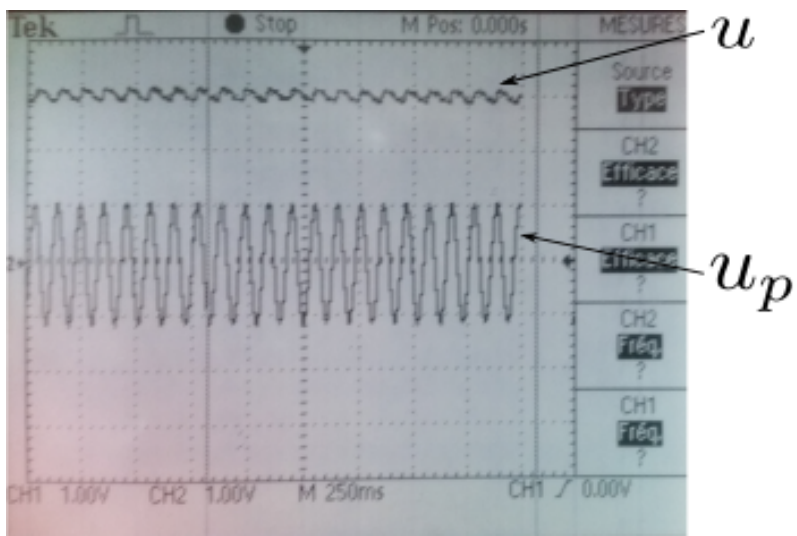

Figure 5: Experimental results: output voltage $u$ with an input voltage $u_{p}=1 V \times \sin (1 \times \pi \times 10 H z \times t)$.

\section{A NEW VERSION OF ELECTRICAL CIRCUIT}

\subsection{The new scheme}

In the previous scheme (Fig. 1), the booster increases the alternating and sine voltage $u_{p}$. It is shown that the output voltage $u_{b}$ of the booster is not anymore sine but is closer to a modified rectangular signal ${ }^{29}$. The objective of the new version of electrical circuit in this section is to directly use this signal as the input of a voltage multiplier, which normally requires a signal from an oscillator. The advantage is that we remove the rectifier stage and the oscillator sub-stage and consequently we reduce the consumption and the voltage loss in the whole circuit. If required however, another adaptor/multiplier stage can be added before the load in order to obtain higher output voltage.

Let Fig. 6-a depicts the suggested second version of electrical circuit. The booster is the same than that of Fig. 1. Its output $u_{b}$ is not anymore a sine but has a shape between a sine and a rectangular signal. This signal is afterwards directly employed as the input of a multiplier, no oscillator being required anymore. However, because $u_{b}$ is not a pure rectangular signal, we suggest to slightly modify the multiplier in order to include a rectifier part such that a DC output $u_{m}$ is ensured. The suggested integrated multiplier/rectifier stage is depicted in Fig. 6-b and is based on a series of diodes and capacitors. Finally, an adaptor/multiplier stage can be again added to increase the DC output $u_{m}$ as well as to adapt the impedence. Without considering the adaptor, the voltage multiplier here is again composed of an oscillator (to provide rectangular signal) and of the multiplier itself, similarly to Fig. 3.

\subsection{Simulation results}

The electrical scheme in Fig. 6 was implemented in LTSPICE and simulated. First, all the capacitors in the multiplier/rectifier were set equal to $10 \mu \mathrm{F}$. A sine input voltage $u_{p}$ with an amplitude of $1 \mathrm{~V}$ and a frequency of $1 \mathrm{~Hz}$ is applied to the whole circuit. Fig. 7 -a shows the results. They show that the output voltage $u$ exceeds $1.2 \mathrm{~V}$, which is more than two times higher than that of the first circuit in Fig. 1. This gain is explained as follows: instead of consuming voltage due to the four diodes based rectifier (see Fig. 1), here we amplify the voltage thanks to the multiplier/rectifier. We now set the capacitors in the multiplier/rectifier equal to $1000 \mu F$. The simulation results are depicted in Fig. 7-b and show an output voltage tending towards $14 \mathrm{~V}$, which is almost thirty times higher than that obtained with the first circuit in Fig. 1. 


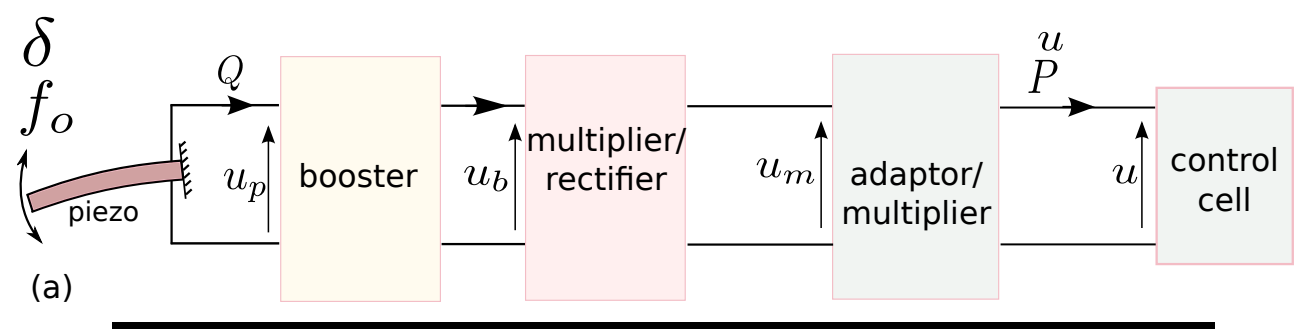

(b)

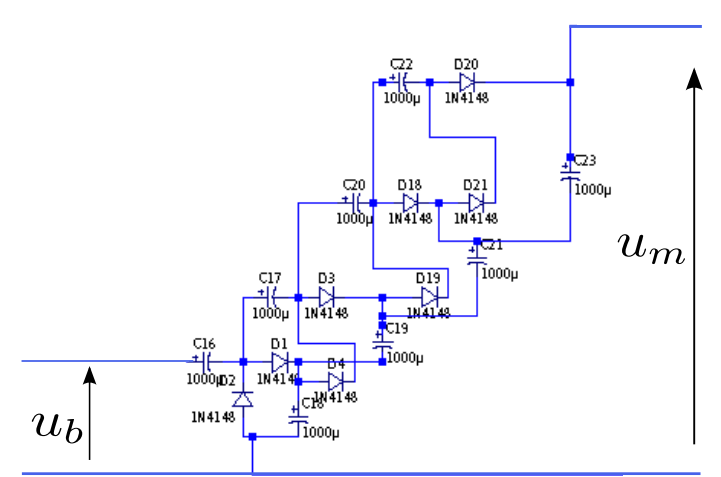

Figure 6: (a): block diagram of the second electrical circuit. (b): scheme of the multiplier/rectifier stage.

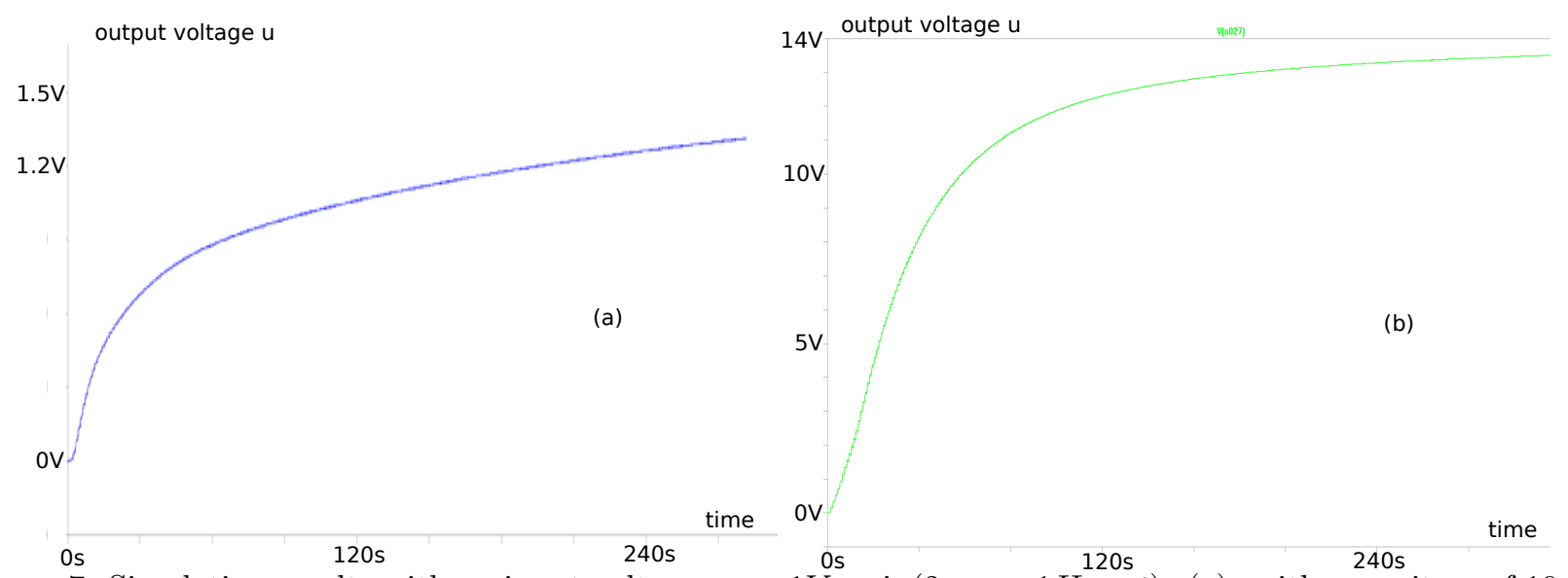

Figure 7: Simulation results with an input voltage $u_{p}=1 V \times \sin (2 \times \pi \times 1 H z \times t)$. (a): with capacitors of $10 \mu F$ in the multiplier/rectifier. (b): with capacitor of $1000 \mu \mathrm{F}$ in the multiplier/rectifier.

\subsection{Experimental results}

The electrical scheme in Fig. 6 has been realized. The used diodes and transistors are similar to those for the first circuit. We use capacitors of $1 \mu \mathrm{m}$ for the multiplier/rectifier. Again, a piezoelectric cantilever structure commercially available was first tested as transducer. Unfortunately its output voltage $u_{p}$ (in the order of tens of milliVolts) was not sufficient to trigger the electrical circuit. Hence, we use a generator to supply $u_{p}$ and to verify the functioning of the electrical circuit. Fig. 8 shows the results when an input voltage $u_{p}$ with an amplitude of $1 \mathrm{~V}$ and a frequency of $1 \mathrm{~Hz}$ is applied. The output $u$ reaches $3 \mathrm{~V}$ which is much higher than the simulation. Again, the reason might be that the voltage consumption in the simulated circuit could differ from that of the realized circuit. 


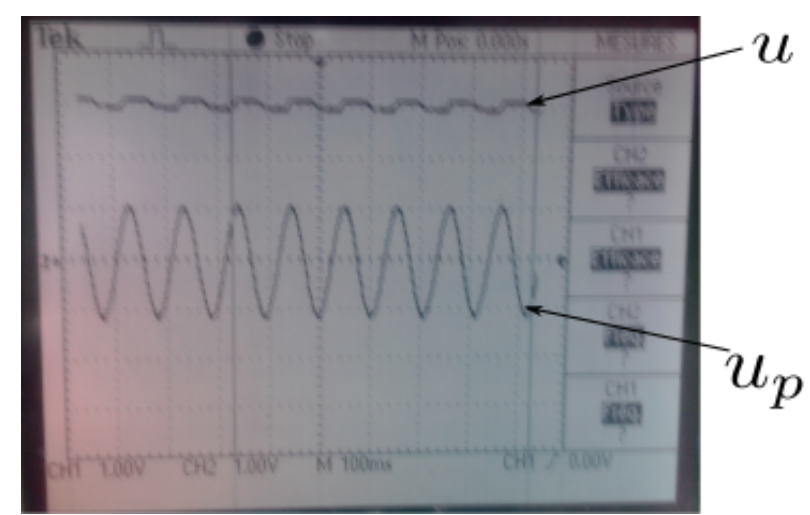

Figure 8: Experimental results: output voltage $u$ with an input voltage $u_{p}=1 V \times \sin (1 \times \pi \times 10 H z \times t)$ and capacitors of $1 \mu F$ in the multiplier/rectifier.

\section{DISCUSSIONS, CONCLUSIONS AND FUTURE WORKS}

In this paper, we suggested two electrical circuits for VPEH devoted to supply devices in distributed control cells. The first suggested circuit was based on already existing electrical stages which we suggested to combine: a booster stage, a rectifier with smoothing capacitor stage and an adaptor/multiplier stage. In the second circuit we suggested to replace the rectifier by a multipier which, instead of having a votage consumption stage, the voltage is increased. Different simulation and experimental tests were carried out and shown the advantage of the second circuit relative to the first one. The experiments also indicated that there was a minimum input voltage required from the piezoelectric structure in order to make the electrical circuit work correctly. This minimum voltage corresponds to the required consumption of the different electrical components. In both circuit, the multiplier stage can be augmented by an adaptor which permits to virtually disconnect the load to be supplied with the upstream stages. The advantage is that the output voltage and output power can be independant from the load.

The components (diodes, transistors) used during the simulation and experimental tests in this paper were standard. The next work consists in replacing all the components by low-consumption components in order to be able to work with low voltage VPEH.

\section{ACKNOWLEDGMENTS}

This work is supported by the national ANR-JCJC C-MUMS-project (National young investigator project ANR12-JS03007.01: Control of Multivariable Piezoelectric Microsystems with Minimization of Sensors). This work is also supported by the LABEX ACTION (ANR-11-LABX-0001-01).

\section{REFERENCES}

[1] Labex ACTION project, "Integrated Smart Systems", (ANR-11- LABX-0001-01), http://www . labex-action.fr/.

[2] ANR C-MUMS project, "Control of Multivariable Piezoelectric Microsystems with Minimization of Sensors", ANR-12-JS03007.01, http://sites.femto-st.fr/c-mums/.

[3] J. Agnus, N. Chaillet, C. Clévy, S. Dembélé, M. Gauthier, Y. Haddab, G. Laurent, P. Lutz, N. Piat, K. Rabenorosoa, M. Rakotondrabe and B. Tamadazte, "Robotic microassembly and micromanipulation at FEMTO-ST," Journal of Micro-Bio Robotics, vol. 8, no. 2, pp. 91-106, 2013.

[4] M. Rakotondrabe, Smart materials-based actuators at the micro/nano-scale: characterization, control and applications, Springer-Verlag, NewYork, 2013.

[5] M. Rakotondrabe, 'Piezoelectric systems for precise and high dynamic positioning: design, modeling, estimation and control', HDR halititation thesis, University of Franche-Comté / FEMTO-ST, November, 2014 . 
[6] K. Rabenorosoa and M. Rakotondrabe, 'Performances analysis of piezoelectric cantilever based energy harvester devoted to mesoscale intra-body robot', SPIE Sensing Technology+Applications; Sensors for Next Generation Robots conference, 9494-28,, Baltimore Maryland USA, April 2015.

[7] M. Rakotondrabe, 'Towards high autonomy energy harvesters based on piezoelectric MEMS', ICT-Energy Nanoenergy Letters, Num.6, pp.55, August 2013.

[8] H.C. Song, et al., 'Multilayer piezoelectric energy scavenger for large current generation', Journal of Electroceramics, 23, 301-304, DOI.1007/s10832-008-9439-9, 2009.

[9] H. Abramovich, et al., 'Multi-layer piezoelectric generator', US patent, US8278800 B2, July 2012.

[10] D. Zhu et al, 'Improving Output Power of Piezoelectric Energy Harvesters using Multilayer Structures', Procedia Engineering, 25, 199-202, 2011

[11] A. Bienaimé, V. Chalvet, C. Clévy, L. Manuel-Gauthier, T. Baron and M. Rakotondrabe, 'Static / dynamic trade-off performance of PZT thickfilm micro-actuators', IOP Journal of Micromechanics and Microengineering, 25075017 doi:10.1088/0960-1317/25/7/075017.

[12] B. Yang, C. Lee, W.L. Lee and S.P. Lim Hybrid energy harvester based on piezoelectric and electromagnetic mechanisms, Journal of . Micro/Nanolith. MEMS MOEMS, 9(2), 023002 Apr-Jun 2010.

[13] X.B. Shan, S.W. Guan, Z.S. Liu, Z.L. Xu and T. Xie, A new energy harvester using a piezoelectric and suspension electromagnetic mechanism, Journal of Zhejiang University Science-A, 14(12), 890-897, 2013.

[14] Dae-Yeong Lee, et al. "Hybrid energy harvester based on nanopillar solar cells and PVDF nanogenerator." Nanotechnology 24 (2013) 175402.

[15] P. Gambier, S. R. Anton, N. Kong, A. Erturk and D.J. Inman, Piezoelectric, solar and thermal energy harvesting for hybrid low-power generator systems with thin-film batteries, Meas. Sci. Technol. 23 015101, 2012.

[16] C. Eichhorn, F. Goldschmidtboeing, P. Woias, 'A frequency tunable piezoelectric energy converter based on a cantilever beam', Proc. of PowerMEMS, pp 309312, 2008.

[17] M. Lallart, S.R. Anton, D.J. Inman, 'Frequency self-tuning scheme for broadband vibration energy harvesting', Journal Intell Mater Syst Struct 21:897906, 2010.

[18] V.R. Challa, M.G. Prasad, F.T. Fisher, 'Towards an autonomous self-tuning vibration energy harvesting device for wireless sensor network applications', Smart Mater Struct, 20:025004, 2011.

[19] L. Tang, Y. Yang, C.K. Soh, 'Broadband vibration energy harvesting techniques', chapter in 'Advances in energy harvesting methods', Springer, ISBN: 978-1-4614-5704-6, 2013.

[20] NEMESIS, 'Novel Energy Materials: Engineering Science and Integrated Systems', ERC-2012-ADG20120216, Project reference: 320963.

[21] Nano Harvest, 'Flexible nanowire devices for energy harvesting', ERC-2014-STG, Project reference: 639052.

[22] NANOGEN, 'Polymer-based piezoelectric nanogenerators for energy harvesting', ERC-2014-STG, Project reference: 639526 .

[23] A. Bartasyte, M. Rakotondrabe, T. Baron and S. Ballandras, 'From green piezoelectric materials to designed hybrid piezoelectric energy harvesters', International Workshop on Advanced Materials Challenges for Alternative Energy Solutions, Incheon, Corée, April 2014.

[24] A. Bartasyte, M. Rakotondrabe, T. Baron and S. Ballandras, 'Can LiNb03 be an alternative for PZT in vibrational energy harvesters?', Materials Challenges in Alternative and Renewable Energy conference, Jeju, Korea, February, 2015.

[25] E. Dallago, et al, 'Electronic interface for piezoelectric energy scavenging system', Solid-State Circuits Conference, 2008.

[26] D. Guyomar, M. Lallart, 'Recent progress in piezoelectric conversion and energy harvesting using nonlinear electronic interfaces and issues in small scale implementation', Micromachines, vol.2(2), 2011.

[27] M. Lallart, 'Small-scale energy harvesting', InTech, ISBN 978-953-51-0826-9, 2012.

[28] Lallart et al, 'Switching delay effects on nonlinear piezoelectric energy harvesting techniques', IEEE Trans Industrial Electronics, 59(1), 2012

[29] A. Badel, "Récupération dénergie et contrle vibratoire par éléments piézoélectriques suivant une approche non linéaire", PhD thesis, INSA Lyon France, 2005.

[30] A. Ertuck and D.J. Inman, 'Piezoelectric energy harvesting', Wiley, ISBN: 978-0-470-68254-8, 2011. 